Full-length article

\title{
Wind of change: Small-scale electricity production and distribution-grid efficiency in Sweden
}

\author{
Mattias Vesterberg ${ }^{\mathrm{a}, \mathrm{b}, *}$, Wenchao Zhou ${ }^{\mathrm{b}, \mathrm{c}}$, Tommy Lundgren ${ }^{\mathrm{a}, \mathrm{b}}$ \\ ${ }^{a}$ Umeå School of Business, Economics and Statistics, Umeå University, Sweden \\ ${ }^{\mathrm{b}}$ Centre for Environmental and Resource Economics, Umeå University, Sweden \\ ${ }^{\mathrm{c}}$ Centre for Regional Science, Umeå University, Sweden
}

\section{A R T I C L E I N F O}

\section{JEL classification:}

C14

D42

Q41

Keywords:

Data envelopment analysis

Bootstrap

Efficiency

\begin{abstract}
A B S T R A C T
In this paper, we measure the technical efficiency for local electricity distribution firms in Sweden, and in particular how small and micro-scale generation affects efficiency scores. Using a two-stage data envelopment analysis to model the technical efficiency and a double bootstrap approach to estimate the determinants of inefficiencies, we show that firms are heterogeneous in terms of inefficiency, but that a large share of small and micro-scale generation is not associated with more inefficient operations.
\end{abstract}

\section{Introduction}

The share of small-scale electricity generation is increasing rapidly in Sweden and elsewhere. For example, between 2007 and 2017, the wind generation, as a share of total domestic generation, increased from less than one percent to more than ten percent. ${ }^{1}$ Furthermore, both small and micro-scale generation are heavily subsidized in Sweden, through both direct subsidies on, e.g., installations on photovoltaics Lindahl (2016), and through a tradable electricity certificate mechanism with a government-set quota to promote renewable energy. This development is expected to continue for the foreseeable future if Sweden is to meet its ambitious climate and energy policy goals of 100 percent of renewable generation by 2045. For example, the Swedish Energy Agency forecast wind generation to be up to 60 TWh in 2050, compared to approximately $20 \mathrm{TWh}$ as of today Energimyndigheten (2018).

Many argue that increased penetration of distributed electricity generation, such as solar and wind, will have profound impacts on the efficiency of electricity distribution (e.g., Mateo et al. (2018), Adefarati and Bansal (2016), Asrari et al. (2016), Jenkins et al. (2017), Cossent et al. (2009)). Contrary to transmission grids, ${ }^{2}$ distribution networks are not designed to accommodate generation, only consumption. An increasing share of intermittent small-scale generation may also pose management, planning, and coordination challenges in the delivery of electricity. On the other hand, the location of generation close to consumption may, for example, reduce networks losses, which would possibly improve network efficiency. In any case, there is little, if any, empirical evidence on the effects of small and micro-scale generation on the efficiency of electricity distribution networks. This issue is becoming increasingly important to study as the penetration of small and micro-scale renewable energy is sure to continue to increase. This paper fills this gap.

In more detail, this paper contributes to the existing literature by being the first to explore how small and micro-scale generation affects the efficiency of electricity distribution operation. We use a two-stage Data Envelopment Analysis (DEA) approach to model the technical efficiency among the approximately 150 local electricity grids in Sweden. The analysis sets out to capture their heterogeneous environment and firm characteristics that might affect their efficiency. Most notably,

\footnotetext{
Financial support from the Swedish Energy Agency (grant number 44340-1) and Jan Wallander's and Tom Hedelius Foundation (grant number W17-0061) is gratefully acknowledged.

* Correspondence to: Samhällsvetarhuset, Biblioteksgränd 6, A24007 Umeå universitet, 90187 Umeå, Sweden.

E-mail address: mattias.vesterberg@umu.se (M. Vesterberg).

1 Source: https://www.energiforetagen.se/statistik/energiaret/.

2 Transmission and distribution refers to the different stages of carrying electricity over poles and wires from generators to end-users. Transmission refers to

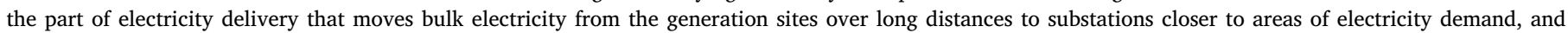

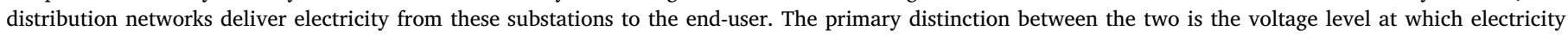
moves in each stage.
} 
we include distributed power from small and micro-scale production, which varies substantially across firm networks, as environmental variables. To a large extent, these small and micro-scale units are wind producing units. To draw inference on how the environmental and firmspecific factors affect the firms operating the grids, a double bootstrap approach, similar in spirit to Simar and Wilson (2007), is employed. In brief, we find that firms in northern Sweden (price areas SE1 and SE2), large firms, and firms with a high customer density, are relatively more efficient. Furthermore, and contrary to previous recent studies (e.g., Lundin (2020)), our findings reveal that there are relatively little differences in efficiency across different types of ownership (which is in line with the findings in Hjalmarsson and Veiderpass (1992). Finally, we find that the effect of small and micro-scale production on grid efficiency is insignificant or slightly positive.

The rest of the paper is structured as follows: in Section 1.1, we describe the Swedish transmission and distribution system and review the recent literature concerning technical and cost efficiency in these markets. In Section 2, we detail the data used in this paper, and we describe the empirical approach in Section 3. The results from our estimation are presented in Section 4, and Section 5 concludes.

\subsection{Background and previous literature}

The Swedish power transmission and distribution system is characterized by a three-tier structure, with the national transmission grid owned and operated by a state-owned utility, Svenska Kraftnät (www. svk.se), about thirteen regional grids owned and operated by the large power generators, and about 150 local distribution grids primarily managed by municipal (approximately 67 percent of the firms) and privately owned entities (13 percent). ${ }^{3}$

The local grids, which distribute electricity to the end-users, are each a monopoly in their region of operation, and they are the focus of our analysis. These firms, typically referred to as Distribution System Operators (DSO's) in the literature, are regulated through a firmspecific revenue cap by the Swedish Energy Market Inspectorate (SEMI, www.ei.se). The revenue cap model can be broken down into three parts of revenue drivers: Controllable costs, non-controllable costs and asset base. These are then adjusted according to efficiency requirements Wallnerström et al. (2017). See Pandur and Jonsson (2015) for details.

The literature on the efficiency of electricity distribution has seen a large expansion. The common findings in the literature are that few firms are fully efficient, but that the efficiency scores vary substantially across firms. These results are typically derived from either DEA or variants of stochastic frontier analysis (SFA). ${ }^{4}$

To give a few examples, Arocena (2008) analyzes the degree of vertical integration and diversification in the electricity industry using DEA on Spanish data on electricity distribution. They show that cost and quality gains from integrating power generation and distribution amount to approximately five percent, whereas diversifying the source of power generation saves between 1.3 and 4.3 percent of costs and quality.

Fallahi et al. (2019) evaluate the efficiency and productivity change of 39 electricity distribution companies in Iran over the 2005-2014 period, and focus on regional heterogeneity in efficiency. Agrell et al. (2005) explore different regulatory schemes for Scandinavian electricity distributors using cost information from a productivity analysis model and an agency theoretical decision model. The authors illustrate how the proposed schemes have considerable advantages compared to the popular CPI-X revenue cap regulation. Giannakis et al. (2005)

\footnotetext{
3 The remaining firms are managed by, e.g., co-operatives

4 DEA and SFA are typically also used by the regulators; for example, in Sweden, the regulator (the Swedish Energy Market Inspectorate) use DEA to estimate efficiency scores in determining revenue cap for the individual DSO (see Energimarknadsinspektionen (2015)).
}

present a quality-incorporated benchmarking study of the electricity distribution firms in the UK, and compute the utilities' technical efficiency of the utilities using DEA technique and productivity change over time through quality-incorporated Malmquist indices. They find that cost-efficient firms do not necessarily exhibit high service quality and that efficiency scores of cost-only models do not show high correlation with those of quality-based models. The results also show that service quality improvements have significantly contributed to the sector's total productivity change.

Other examples of efficiency analysis of electricity distribution include Filippini et al. (2018), Bobde and Tanaka (2018) and Mydland et al. (2019). For applications to the Nordic context, see Kuosmanen (2012), Korhonen and Syrjänen (2003), Edvardsen and Førsund (2003), Førsund and Kittelsen (1998), and more recently, Kumbhakar and Lien (2017), Kumbhakar et al. (2020). These latter papers have in particular focused on distinguishing between short- and long-run inefficiencies (usually labeled transient or persistent inefficiency) for both technical inefficiency and allocative inefficiency, respectively.

For studies of the efficiency of electricity distribution in Sweden, Hjalmarsson and Veiderpass (1992) illustrate that there are little variation in efficiency across time, ownership and location, and Lundin (2020) examines the effects of privatization, in the form of acquisitions, in the Swedish electricity distribution sector. Somewhat surprising, and as already alluded to, although the literature on the drives of inefficiency is substantial, we have not found any previous literature on how this heterogeneity is associated with the share of micro- and small-scale generation.

A common way to analyze the drivers of the observed heterogeneity in efficiency scores obtained from DEA is to employ a two-stage strategy where efficiency scores are calculated, and regression techniques are then used to explain the difference in efficiency across DSOs (Simar and Wilson, 2007). Llorca et al. (2014) use a latent class approach to cluster DSOs in the US market according to technical differences and estimate efficiency within the classes using DEA. They find that minimum temperature and growth in power demands promote efficiency. Çelen (2013) employs a two-stage DEA analysis and a Tobit regression to explain efficiency scores for Turkish distribution firms and shows that customer density and diversified ownership affected firm performance. Dai and Kuosmanen (2014) use a clustering method to group distribution companies according to differences in environmental variables and find a small positive correlation between customer density and productive efficiency of distribution companies in Finland. In a recent paper, Xie et al. (2018), study Chinese DSOs by a metafrontier approach, where environmental factors are used to explain bootstrapped efficiency scores through a Tobit regression. Of interest to the current paper is that they find that increasing proportion of renewable generation decrease efficiency.

\section{Data}

The data used for this analysis is publicly available from the regulator's website (Swedish Energy Market Inspectorate, see www.ei.se), and includes data on all $(N=155)^{5}$ the Swedish DSOs' financial and technological data. This data are used by the regulator for regulation. The data on costs come from each firm's final revenue-cap report for the supervisory period 2012-2018, published by the regulator. However, the data only includes information about small-scale production for 2014-2017, so we focus our analysis on these years. Summary statistics of the key variables included in the empirical modeling are presented in Tables 1 and 2. All monetary values in this paper are in 2014 SEK.

The first thing to notice is the substantial heterogeneity across firms in terms of both costs and technical characteristics. Capital cost,

\footnotetext{
5 Worth noting is that this is a substantially larger sample size than, for example, Filippini et al. (2018) where $N=28$.
} 
Table 1

Descriptive statistics, Swedish local distribution service operators, 2014-2017.

\begin{tabular}{llrrrr}
\hline Variables & Unit & Min & \multicolumn{1}{c}{ Mean } & Max & SD \\
\hline Capital costs & MSEK & 824 & 116859 & 3889155 & 368506 \\
Controllable operational costs & MSEK & 1097 & 52049 & 1533303 & 157920 \\
Non-controllable operational costs & MSEK & 278 & 56998 & 1821909 & 185744 \\
& & & & 812178 & 36257 \\
Number of customers & & 310 & 33748 & 17700 & 4048 \\
Number of netstations & & 27 & 1072 & 102327 \\
Maximum power output & MW & 1 & 418027 & 332 \\
Distributed low voltage electricity & MWh & 3469 & 155734 & 3283274 & 411903 \\
Distributed high voltage electricity & MWh & 0 & & \\
\hline
\end{tabular}

Table 2

Descriptive statistics, Swedish local distribution service operators, 2014-2017.

\begin{tabular}{lllrrrr}
\hline Variables & Unit & Min & Median & Mean & Max & SD \\
\hline Customer density & customers/km & 3.01 & 10.33 & 12.10 & 43.00 & 7.03 \\
Micro scale production & $\%$ & 0.00 & 0.02 & 0.16 & 21.24 & 1.36 \\
Small scale production & $\%$ & 0.00 & 1.42 & 5.99 & 96.41 & 12.13 \\
Power distributed to border point & $\%$ & 0.00 & 0.00 & 2.44 & 68.44 & 9.26 \\
Vertical integration & $\%$ & 0.00 & 0.14 & 9.85 & 100.00 & 17.82 \\
\hline
\end{tabular}

illustrated in Table 1 is a good example, varying from 824 MSEK to over 400000 MSEK. Similarly, the number of customers varies from 310 to over a hundred thousand. Turning to the key variable of this paper, presented in Table 2, we note that the average share of small-scale production is small; less than two percent, but that for some firms, this share is very large: more than 95 percent. As is illustrated by Tables A.1-A.4 in Appendix A, there are some interesting differences in firm characteristics across small-scale production levels. For example, firms with small-scale production above the mean on average are somewhat smaller, with lower costs and fewer customers, but the heterogeneity within this group is large.

\section{Empirical approach}

\subsection{Efficiency measurement}

Similar to previous literature, efficiency is defined in this paper as the ratio of optimal to actual inputs, holding outputs fixed. Assume that firms use a vector of $N$ inputs $x=\left(x_{1}, \ldots, x_{N}\right)$ to produce a vector of $M$ outputs $y=\left(y_{1}, \ldots, y_{M}\right)$. The technology can be defined as: $T=\{(x, y): x$ can produce $y\}$, which is assumed to be closed and bounded, implying that a finite amount of inputs can only produce a finite amount of outputs. To apply the production technology $T$ to empirical applications, we can represent it by using DEA. Assume that there are $k=1, \ldots, K$ observations of inputs and outputs, each of which is associated with a firm. The technology that allows for constant returns to scale (CRS) ${ }^{6}$ can be represented by:

$$
\begin{aligned}
& T=\{(x, y): \\
& \sum_{k=1}^{K} z_{k} y_{k m} \geq y_{m}, m=1, \ldots, M \\
& \sum_{k=1}^{K} z_{k} x_{k n} \leq x_{n}, n=1, \ldots, N \\
& \left.z_{k} \geq 0, k=1, \ldots, K\right\}
\end{aligned}
$$

The intensity variables, $z_{k}, k=1, \ldots, K$ serve as coefficients to perform linear combinations of all observed firms' inputs and outputs, and determine the reference point. Then, the DEA model for measuring

\footnotetext{
${ }^{6}$ We compare with a VRS specification, and find very similar results.
}

the efficiency of firm, $k^{\prime}=1, \ldots, K$ can be written as:

$$
\begin{aligned}
& \delta_{k^{\prime}}=\min _{z_{k}, \delta} \delta \\
& \sum_{k=1}^{K} z_{k} y_{k m} \geq y_{k^{\prime} m}, m=1, \ldots, M \\
& \sum_{k=1}^{K} z_{k} x_{k n} \leq \delta x_{k^{\prime} n}, n=1, \ldots, N \\
& z_{k} \geq 0, k=1, \ldots, K
\end{aligned}
$$

The value of $\delta_{k}$ is in the range of $(0,1]$. An efficient firm has $\delta_{k}=1$, while an inefficient firm will have $0<\delta_{k}<1$ : a higher value indicates higher efficiency.

\subsection{The econometric model}

We use an econometric model to examine what factors affect efficiency. This is achieved by regressing the efficiency estimates on a set of environmental and control variables. Suppressing subscript $t$ denoting year, the regression equation can be written as:

$\delta_{k}=f \beta+\varepsilon_{k}$

where $\delta_{k}$ is the efficiency score obtained from estimating Eq. (1), $f$ is the vector of explanatory variables, e.g., small-scale production, $\beta$ are parameters to be estimated, and $\varepsilon_{k}$ is the disturbance term.

To estimate Eq. (3), we can use the method of ordinary least squares (OLS). An alternative method is to treat $\delta_{k}$ as being censored (for $\delta_{k}>1$ ) and use the Tobit model. However, Simar and Wilson (2007) point out that there exist serious problems associated with estimating Eq. (3) using the usual estimation methods. Specifically, when $\delta_{k}$ is used as the dependent variable in regression analysis, two issues must be considered. One issue is that $\delta_{k}$ is serially correlated. Another issue is that $\delta_{k}$ is biased, though consistent. Simar and Wilson (2007) show that it is not possible to provide consistent and valid inference for the coefficients estimates which are obtained by using either OLS or Tobit. To overcome the difficulty, Simar and Wilson (2007) suggest a double bootstrap procedure, which yields consistent and valid inference for $\beta$ in Eq. (3) by using the method of maximum likelihood estimation. Briefly, the first bootstrap is used to produce a bias-corrected $\hat{\delta}_{k}$ for $\delta_{k}$; replacing $\delta_{k}$ with $\hat{\delta}_{k}$, and the second bootstrap is used to provide valid 
inference about $\beta$. The Simar and Wilson (2007) bootstrap algorithm is applied to our regression analysis. ${ }^{7}$

A key criticism of standard DEA is that the method does not lend itself to statistical inference concerning the efficiency scores and that outliers in the data could be very influential for the results. Another common criticism of the two-stage procedure is that determinants used in the second stage could be important in that they influence the first stage scores, and therefore should have been included as variables in that stage already. This problem could be remedied by using stochastic frontier analysis (SFA), where it is possible to do this kind of oneshot estimation of both stages (the inefficiency is modeled explicitly as dependent on determinants when generating the scores). This necessitates parameterizing the frontier function, which can be restrictive and significantly impact the results.

Simar and Wilson (2011) discuss several statistical challenges using two-stage DEA. They claim only two statistical models have been proposed in which two-stage regressions are statistically meaningful and provide consistent estimation: Simar and Wilson (2007) propose a truncated regression that provides consistent estimation in the second stage, and the model proposed in Banker and Natarajan (2008). Simar and Wilson (2011) propose that two-stage OLS estimation is consistent only under peculiar assumptions on the data-generating process that limits applicability. They also comment on ad-hoc specifications of twostage regressions that ignore the part of the data-generating process that yields data used to obtain the initial DEA estimates. The two-stage DEA is widely used in empirical applications (hundreds of papers, and counting). We do not claim to progress methodology in this paper, but simply follow a large previous literature and use an empirical methodology that is commonly accepted in applied work today. We apply the two-stage estimation procedure proposed by Simar and Wilson (2007) as this still seem to be the state-of-the-art approach, but we are aware of its potential flaws and try to mitigate them as much as possible (more on this below).

\subsection{The specification of empirical models}

\subsubsection{The DEA specification}

We specify two DEA models with different output variables. In our first specification, $M 1$, we follow exactly the DEA model specification used by the Swedish regulator, SEMI, has used to estimate efficiency scores in determining revenue cap for the individual DSOs (see page 71 in Energimarknadsinspektionen (2015).

The input and output variables for this specification are:

$$
\begin{aligned}
& \mathrm{X} 1=\text { controllable operational costs (MSEK); } \\
& \mathrm{X} 2=\text { non-controllable operational costs (MSEK); } \\
& \mathrm{X} 3=\text { capital costs (MSEK). }
\end{aligned}
$$

The output variables are:

$$
\begin{aligned}
& \text { Y1 = number of customers; } \\
& \text { Y2 = number of net stations; } \\
& \text { Y3 = maximum power outputs (MWh); } \\
& \text { Y4 = distributed low-voltage electricity (MWh); } \\
& \text { Y5 = distributed high-voltage electricity (MWh). }
\end{aligned}
$$

The regulator provides some brief motivations for this specification, including that (i) the output variables are plausible cost drivers; (ii) the model gives rise to higher efficiency scores than models with, e.g., only capital costs as input; (iii) in principal, it is reasonable to include also non-controllable costs; (iv) the model produces similar results to an alternative specification with only capital costs as inputs. See Energimarknadsinspektionen (2015) for additional discussions.

7 The bootstrap algorithm developed by Simar and Wilson (2007) is designed for an output-oriented efficiency measure. For the algorithm adapted for an input-oriented measure, see Zhang et al. (2016).
The second DEA model, $M 2$, is consistent with the DEA model of Hjalmarsson and Veiderpass (1992) in which the efficiency of the Swedish electricity distribution was studied. . From the viewpoint of economic theory, we consider that these variables are closely associated with the firm's revenue. This perspective motivates the second model, and this specification also allows us to compare with previous literature for Sweden. Specifically, $M 2$ includes the same input variables as $M 1$ but with the output variables:

$$
\begin{aligned}
& \mathrm{Y} 1=\text { number of customers; } \\
& \mathrm{Y} 4=\text { distributed low-voltage electricity (MWh); } \\
& \mathrm{Y} 5=\text { distributed high-voltage electricity (MWh). }
\end{aligned}
$$

To create an incentive for consolidation in the electricity distribution sector and realize economies of scale, SEMI suggests using DEA models with CRS in calculating efficiency scores for Swedish DSOs, even though there is scale effect (Energimarknadsinspektionen, 2015). We follow the SEMI's method and use CRS in both DEA models but compare our results to a VRS model (results are available upon request), which we find to produce very similar results as our main specification.

\subsubsection{The econometric model specification}

For each of the two DEA models ( $M 1$ and $M 2$ ), we separately estimate the econometric model corresponding to Eq. (3), including eight independent variables. These variables are:

$f_{1}=$ customer density, which is measured by the number of customers per kilometer power lines;

$f_{2}=$ firm size, a binary variable, which is equal to 1 if a firm is large and 0 otherwise. The size is determined relative to the median value of the number of customers in the population;

$f_{3}=$ electricity price area, a dummy variable, where price area SE1 (out of SE1, SE2, SE3 and SE4) is taken as baseline;

$f_{4}=$ small-scale production, which is measured by the share of delivered electricity that is produced by small-scale generation plants (e.g., wind power plant) in the total delivery;

$f_{5}=$ micro-scale production, which is measured by the share of delivered electricity that is from micro-scale generation plants (e.g., solar panel) in the total delivery;

$f_{6}=$ degree of vertical integration, which is measured by the share of energy produced by the DSO relative to the total delivered electricity;

$f_{7}=$ power distributed to border point, which is measured by the share of electricity that is delivered to the border point;

$f_{8}=$ a year dummy variable that is included to capture the efficiency change over time, where year 2014 is the baseline.

In addition, we also estimate specifications with interaction terms between small-scale generation and customer density, and between small-scale generation and firm size.

To obtain meaningful estimation results in the second stage, environmental factors must satisfy the "separability condition", which means that the environmental factors used in the second stage as independent variables can only affect the distribution of the efficiencies, but not the technology frontier itself, or the attainable input-output combinations Simar and Wilson (2007). We investigate our data using Pearson's correlation test. ${ }^{8}$ The correlation coefficient matrix is presented in Table A.5 in Appendix A. The correlation matrix shows that factors $f_{4}, f_{5}, f_{6}$, and $f_{7}$ are not significantly correlated with any of the input and output variables, while $f_{1}$ is not significantly correlated with input variables X2 and X3. Accordingly, it seems reasonable to assume

\footnotetext{
8 A more formal empirical test for the validity of separability condition is suggested by Daraio et al. (2018). However, with the variables correlation results at hand, we do not deem it necessary to do further testing.
} 
Table 3

Average estimates of technical efficiency (bias-corrected) by year, Swedish local distribution service operators, 2014-2017. (M1).

\begin{tabular}{llllll}
\hline Year & Mean & Median & Min & Max & SD \\
\hline 2014 & 0.7314 & 0.7318 & 0.4442 & 0.9458 & 0.1166 \\
2015 & 0.7132 & 0.7095 & 0.4318 & 0.9407 & 0.1236 \\
2016 & 0.7281 & 0.7230 & 0.5084 & 0.9316 & 0.0993 \\
2017 & 0.7587 & 0.7562 & 0.5421 & 0.9525 & 0.1001 \\
\hline
\end{tabular}

Table 4

Average estimates of technical efficiency (bias-corrected) by year, Swedish local distribution service operators, 2014-2017. (M2).

\begin{tabular}{llllll}
\hline Year & Mean & Median & Min & Max & SD \\
\hline 2014 & 0.6711 & 0.6423 & 0.3348 & 0.9554 & 0.1374 \\
2015 & 0.6529 & 0.6264 & 0.3201 & 0.9577 & 0.1393 \\
2016 & 0.6625 & 0.6490 & 0.3424 & 0.9498 & 0.1333 \\
2017 & 0.6925 & 0.6764 & 0.3805 & 0.9705 & 0.1333 \\
\hline
\end{tabular}

Table 5

Estimated parameters and confidence intervals for the regression model (dependent variable: $\left.e_{i}\right)$. (M1).

\begin{tabular}{lcl}
\hline Independent variables & Coefficients & Confidence interval (95\%) \\
\hline (Intercept) & $0.7277^{* * *}$ & $(0.6884,0.7678)$ \\
Large firm & $0.0530^{* * *}$ & $(0.0370,0.0699)$ \\
Customer density & $0.0049^{* * *}$ & $(0.0036,0.0062)$ \\
Small scale production & 0.0004 & $(-0.0003,0.0010)$ \\
Micro scale production & -0.0029 & $(-0.0086,0.0031)$ \\
Power distributed to border point & -0.0006 & $(-0.0016,0.0005)$ \\
Vertical integration & 0.0004 & $(-0.0002,0.0010)$ \\
Price area SE2 & 0.0141 & $(-0.0333,0.0611)$ \\
Price area SE3 & $-0.0826^{* * *}$ & $(-0.1224,-0.0446)$ \\
Price area SE4 & $-0.1426^{* * *}$ & $(-0.1842,-0.1034)$ \\
y2015 & -0.0183 & $(-0.0400,0.0026)$ \\
y2016 & -0.0022 & $(-0.0237,0.0195)$ \\
y2017 & $0.0282^{* *}$ & $(0.0058,0.0513)$ \\
Sigma & $0.0959^{* * *}$ & $(0.0903,0.1020)$ \\
Log likelihood: 582.2 on 14 degree of freedom. & \\
Number of observations: 606 & & \\
\hline
\end{tabular}

Notes: *,* , and $* * *$ represent significance at the 10,5 , and $1 \%$ levels, respectively.

that the environmental factors we used may only affect the distribution of efficiencies, but not the attainable set. Thus, the regression analysis performed in the second stage provides meaningful results.

\section{Results}

Our results from the first DEA model, $M 1$, are presented in Table 3 (and in Tables B.1 and B.2 in Appendix B), and for the second DEA model, $M 2$, in Table 4 (and in Tables B.3 and B.4 in Appendix B). The regression results, where we explore determinants for efficiency scores, are presented in Tables 5 and 6 (and in Tables C.1-C.8 in Appendix C). These results reveal several interesting results. First, we find substantial heterogeneity in efficiency among Swedish DSOs. This is in line with the findings in previous literature, as discussed in our literature review. The results are also very similar to the regulator's own result, which is expected given that we use a similar approach (see Energimarknadsinspektionen (2015)). Furthermore, we find that there is not much variation in efficiency across the four years (Tables 3 and 4), as expected due to the short time span or our data.

There is a relatively large heterogeneity in efficiency across pricing areas, as illustrated by Tables B.1 and B.3, with a higher efficiency in the most northern pricing areas (SE1 and SE2). This is also evident in Tables 5 and 6, where we see that firms in price area 1 are significantly more efficient than firms in price areas 2,3 and 4 . One possible explanation to this result is that a majority of electricity is
Table 6

Estimated parameters and confidence intervals for the regression model (dependent variable: $\left.e_{i}\right)$. (M2).

\begin{tabular}{lcl}
\hline Independent variables & Coefficients & Confidence interval (95\%) \\
\hline Intercept) & $0.5509^{* * *}$ & $(0.5116,0.5910)$ \\
sizeLarge & $0.0480^{* * *}$ & $(0.0319,0.0660)$ \\
Customer density & $0.0131^{* * *}$ & $(0.0117,0.0146)$ \\
Small scale production & 0.0001 & $(-0.0006,0.0007)$ \\
Micro scale production & -0.0007 & $(-0.0063,0.0051)$ \\
Power distributed to border point & $-0.0017^{* * *}$ & $(-0.0029,-0.0006)$ \\
Vertical integration & 0.0001 & $(-0.0004,0.0007)$ \\
Price area SE2 & $0.0698^{* * *}$ & $(0.0243,0.1159)$ \\
Price area SE3 & $-0.0614^{* * *}$ & $(-0.1014,-0.0238)$ \\
Price area SE4 & $-0.1105^{* * *}$ & $(-0.1523,-0.0711)$ \\
y2015 & -0.0158 & $(-0.0376,0.0057)$ \\
y2016 & -0.0053 & $(-0.0275,0.0170)$ \\
y2017 & $0.0231^{* *}$ & $(0.0006,0.0458)$ \\
Sigma & $0.0958^{* * *}$ & $(0.0902,0.1015)$ \\
Log likelihood: 583.3 on 14 degree of freedom. & \\
Number of observations: 606 & & \\
\hline
\end{tabular}

Notes: *,**, and *** represent significance at the 10,5 , and $1 \%$ levels, respectively.

produced in the northern part of Sweden (e.g., hydropower) whereas most consumption is in the southern Sweden. The long distance of transmission from North to South results in a large net loss. As a result, firms in areas SE1 and SE2 are more efficient.

There is relatively little difference in efficiency across ownership types, as illustrated in Tables B.2 and B.4. This finding is somewhat surprising because it seems likely that firms that are owned by, e.g., municipalities have a somewhat different objective, compared to privately owned firms. For example, firms owned by municipalities may be concerned by, e.g., equity, or other objectives that are not necessarily compatible with efficiency. Contrary to previous studies (e.g., Lundin (2020), our findings reveal that this is not the case. Furthermore, large firms, and firms with high customer density, are more efficient; see, for example, Tables 5 and 6 . A plausible explanation to this is that distribution of electricity is characterized by economies of scale.

Firm size (above median number of customers) and customer density are positively associated with efficiency in all specification, whereas the effects of power distributed to border point are statistically significant and negative in $M 1$ and statistically insignificant in $M 2$, and the degree of vertical integration is insignificant in both specifications.

We find small-scale production to be positively correlated with efficiency scores in some models (e.g., Tables C.2 and C.4), but the effect is small and in other specifications (e.g., Tables 5 and 6), it is not significantly different from zero. Most importantly, we find no negative effect of small scale production on efficiency in any of our specifications. ${ }^{9}$ This tells us that a large share of small-scale generation does not lead to electricity distribution inefficiencies. This is an important result, given that the share of small-scale generation is increasing steadily in Sweden and elsewhere.

\section{Conclusions and policy implications}

In this paper, we study how the technical efficiency of Swedish electricity distribution firms vary across firm characteristics. Of particular interest is how the increasing share of small and micro-scale generation affects inefficiency. Even if small and micro-scale generation on average is relatively small in Sweden, heterogeneity across firms in this respect is substantial, which makes Sweden a useful context for such analysis. Using detailed firm-level data and a two-stage Data

\footnotetext{
9 In addition, as illustrated by Table C.9, there is no statistically significant relation between small scale generation and net losses.
} 
Table A.1

Descriptive statistics, Swedish local distribution service operators, 2014-2017, small scale production $\geq$ mean.

\begin{tabular}{|c|c|c|c|c|c|}
\hline Variables & Unit & Min & Mean & Max & SD \\
\hline Capital costs & MSEK & 1352 & 75648 & 1304059 & 167478 \\
\hline Controllable operational costs & MSEK & 1162 & 35314 & 730574 & 87033 \\
\hline Non-controllable operational costs & MSEK & 476 & 35675 & 588586 & 82249 \\
\hline Number of customers & & 512 & 22391 & 564677 & 67451 \\
\hline Number of netstations & & 40 & 707 & 9555 & 1526 \\
\hline Maximum power output & MW & 3 & 93 & 1826 & 230 \\
\hline Distributed low voltage electricity & MWh & 3469 & 270116 & 5718447 & 713748 \\
\hline Distributed high voltage electricity & MWh & 0 & 111958 & 2302841 & 312113 \\
\hline
\end{tabular}

Table A.2

Descriptive statistics, Swedish local distribution service operators, 2014-2017, small scale production $<$ mean.

\begin{tabular}{llrrrr}
\hline Variables & Unit & Min & \multicolumn{1}{c}{ Mean } & Max & SD \\
\hline Capital costs & MSEK & 824 & 130415 & 3889155 & 413080 \\
Controllable operational costs & MSEK & 1097 & 57554 & 1533303 & 174806 \\
Non-controllable operational costs & MSEK & 278 & 64012 & 1821909 & 208471 \\
& & & & \\
Number of customers & & 310 & 37483 & 112178 & 36257 \\
Number of netstations & & 27 & 199 & 17700 & 4579 \\
Maximum power output & MW & 1 & 466682 & 10294043 & 1363016 \\
Distributed low voltage electricity & MWh & 4272 & 170135 & 3283274 & 439155 \\
Distributed high voltage electricity & MWh & 0 & &
\end{tabular}

Table A.3

Descriptive statistics, Swedish local distribution service operators, 2014-2017, small scale production $\geq$ mean.

\begin{tabular}{lllrrrr}
\hline Variables & Unit & Min & Median & \multicolumn{1}{c}{ Mean } & Max & SD \\
\hline Customer density & customers/km & 3.29 & 8.45 & 9.99 & 42.90 \\
Micro scale production & $\%$ & 0.00 & 0.02 & 0.51 & 21.24 & 2.07 \\
Small scale production & $\%$ & 6.02 & 15.21 & 20.62 & 96.41 \\
Power distributed to border point & $\%$ & 0.00 & 0.00 & 4.79 & 68.44 & 17.42 \\
Vertical integration & $\%$ & 0.00 & 0.00 & 15.19 & 85.47 & 23.86 \\
\hline
\end{tabular}

Table A.4

Descriptive statistics, Swedish local distribution service operators, 2014-2017, small scale production $<$ mean.

\begin{tabular}{|c|c|c|c|c|c|c|}
\hline Variables & Unit & Min & Median & Mean & Max & SD \\
\hline Customer density & customers $/ \mathrm{km}$ & 3.01 & 10.92 & 12.79 & 43.00 & 7.19 \\
\hline Micro scale production & $\%$ & 0.00 & 0.02 & 0.04 & 2.11 & 0.12 \\
\hline Small scale production & $\%$ & 0.00 & 0.27 & 1.18 & 5.76 & 1.56 \\
\hline Power distributed to border point & $\%$ & 0.00 & 0.00 & 1.66 & 63.86 & 7.23 \\
\hline Vertical integration & $\%$ & 0.00 & 0.54 & 8.10 & 100.00 & 14.94 \\
\hline
\end{tabular}

Table A.5

Correlation matrix of Pearson correlation coefficients.

\begin{tabular}{|c|c|c|c|c|c|c|c|c|c|c|c|c|}
\hline & $\mathrm{X} 1$ & $\mathrm{X} 2$ & X3 & Y1 & $\mathrm{Y} 2$ & Y3 & Y4 & Y5 & $f_{1}$ & $f_{4}$ & $f_{5}$ & $f_{6}$ \\
\hline \multicolumn{13}{|l|}{$\mathrm{X} 1$} \\
\hline $\mathrm{X} 2$ & $0.97^{* * *}$ & & & & & & & & & & & \\
\hline X3 & $0.99^{* * *}$ & $0.97^{* *}$ & & & & & & & & & & \\
\hline Y1 & $0.98^{* * *}$ & $0.97^{* *}$ & $0.96^{* *}$ & & & & & & & & & \\
\hline Y2 & $0.93^{* *}$ & $0.96^{* *}$ & $0.95^{* *}$ & $0.89 * *$ & & & & & & & & \\
\hline Y3 & $0.50^{* *}$ & $0.50^{* *}$ & $0.49^{* * *}$ & $0.50^{* * *}$ & $0.48^{* *}$ & & & & & & & \\
\hline Y4 & $0.98^{* * *}$ & $0.98^{* *}$ & $0.97^{* * *}$ & $1.00 * *$ & $0.92^{* *}$ & $0.50^{* *}$ & & & & & & \\
\hline Y5 & $0.93^{* * *}$ & $0.92^{* *}$ & $0.91^{* *}$ & $0.96^{* *}$ & $0.82^{* *}$ & $0.47^{* *}$ & $0.94 * *$ & & & & & \\
\hline$f_{1}$ & $0.12^{* *}$ & 0.08 & 0.07 & $0.20^{* *}$ & $-0.08^{*}$ & 0.03 & $0.15^{* *}$ & $0.24 * *$ & & & & \\
\hline$f_{4}$ & -0.04 & -0.03 & -0.03 & -0.05 & -0.01 & -0.04 & -0.04 & -0.04 & $-0.20^{* *}$ & & & \\
\hline$f_{5}$ & 0.00 & 0.00 & 0.00 & 0.00 & 0.00 & -0.01 & 0.00 & -0.01 & -0.05 & $0.14^{* *}$ & & \\
\hline$f_{6}$ & 0.03 & 0.01 & 0.04 & 0.02 & 0.04 & 0.00 & 0.02 & 0.02 & -0.01 & 0.01 & -0.04 & \\
\hline$f_{7}$ & -0.01 & -0.01 & -0.01 & -0.02 & 0.01 & 0.04 & -0.02 & -0.03 & $-0.22 * *$ & 0.02 & -0.02 & $0.56^{* *}$ \\
\hline
\end{tabular}

Note: * and $* *$ represent significance at the $5 \%$ and $1 \%$ levels, respectively.

Envelopment Analysis (DEA) approach to model the technical efficiency among the approximately 150 local electricity grids in Sweden, we find that efficiency scores vary substantially across firms, but that small and micro-scale generation does not lead to a decrease in efficiency.

In addition to these results, we also show that there is relatively little difference in efficiency across different types of ownership, which stands in contrast to some of the recent literature Lundin (2020) but are in line Hjalmarsson and Veiderpass (1992), among others. Finally, we show that both firm size and customer density are positively correlated with efficiency, and these results are in line with, e.g., Hjalmarsson and Veiderpass (1992). Finally, it is important to note that even though, for example, small and micro-scale generation does not seem to be associated with inefficiencies in the distribution of electricity, many firms are still inefficient in their operations, and measures should be taken to reduce such inefficiencies. 
Table B.1

Average estimates of technical efficiency (bias-corrected) by electricity price area (Epa), Swedish local distribution service operators, 2014-2017. (M1).

\begin{tabular}{llllll}
\hline epa & 2014 & 2015 & 2016 & 2017 & Mean \\
\hline SE1 & 0.8052 & 0.8152 & 0.7162 & 0.7738 & 0.7776 \\
SE2 & 0.8143 & 0.7861 & 0.8033 & 0.8301 & 0.8084 \\
SE3 & 0.7376 & 0.7195 & 0.7310 & 0.7607 & 0.7372 \\
SE4 & 0.6703 & 0.6497 & 0.6956 & 0.7242 & 0.6850 \\
Avg. & 0.7569 & 0.7426 & 0.7365 & 0.7722 & 0.7521 \\
\hline
\end{tabular}

Table B.2

Average estimates of technical efficiency (bias-corrected) by ownership, Swedish local distribution service operators, 2014-2017. (M1).

\begin{tabular}{llllll}
\hline Ownership & 2014 & 2015 & 2016 & 2017 & Mean \\
\hline Municipal & 0.7344 & 0.7144 & 0.7357 & 0.7648 & 0.7373 \\
Private & 0.7567 & 0.7434 & 0.7539 & 0.7860 & 0.7600 \\
Economic org & 0.7041 & 0.6878 & 0.6842 & 0.7178 & 0.6985 \\
Avg. & 0.7318 & 0.7152 & 0.7246 & 0.7562 & 0.7319 \\
\hline
\end{tabular}

Table B.3

Average estimates of technical efficiency (bias-corrected) by electricity price area, Swedish local distribution service operators, 2014-2017. (M2).

\begin{tabular}{llllll}
\hline epa & 2014 & 2015 & 2016 & 2017 & Mean \\
\hline SE1 & 0.6579 & 0.6935 & 0.6005 & 0.6173 & 0.6423 \\
SE2 & 0.7633 & 0.7216 & 0.7235 & 0.7480 & 0.7391 \\
SE3 & 0.6730 & 0.6546 & 0.6605 & 0.6921 & 0.6700 \\
SE4 & 0.6340 & 0.6147 & 0.6575 & 0.6881 & 0.6486 \\
Avg. & 0.6820 & 0.6711 & 0.6605 & 0.6864 & 0.6750 \\
\hline
\end{tabular}

Table B.4

Average estimates of technical efficiency (bias-corrected) by ownership, Swedish local distribution service operators, 2014-2017. (M2).

\begin{tabular}{llllll}
\hline Ownership & 2014 & 2015 & 2016 & 2017 & Mean \\
\hline Municipal & 0.7056 & 0.6841 & 0.6981 & 0.7251 & 0.7032 \\
Private & 0.6508 & 0.6224 & 0.6229 & 0.6626 & 0.6397 \\
Economic org & 0.5664 & 0.5659 & 0.5617 & 0.5894 & 0.5708 \\
Avg. & 0.6409 & 0.6241 & 0.6276 & 0.6590 & 0.6379 \\
\hline
\end{tabular}

From a policy perspective, our findings of no effect of small and micro-scale generation on the efficiency of electricity distribution is good news as Sweden's ambition is to increase renewable generation further, and thus more small/micro-scale units, in the electricity production system. Our results suggest that this will not harm the efficiency of the DSOs, and that the regulator does not need to take this into account when regulation distribution firms, at least not in the short run. However, the share of small and micro-scale generation in Sweden are still relatively small, and our findings of no effect of such distributed generation on the efficiency of electricity distribution may change as these shares continue to increase. Here, a more structural model of electricity distribution in relation to small and micro-scale generation could be used to predict the long-term effects, and is suggested for further research. Another suggestion for further research is to explore the effects of small and micro-scale generation on regional grids and the transmission grid.

\section{Appendix A. Additional descriptive statistics}

Tables A.1-A.5

\section{Appendix B. Additional results, DEA model}

Table C.1

Estimated parameters and confidence intervals for the regression model (dependent variable: $e_{i}$ ). ( $M 1$ with interaction term)

\begin{tabular}{lcl}
\hline Independent variables & Coefficients & Confidence interval (95\%) \\
\hline (Intercept) & $0.7277^{* * *}$ & $(0.6889,0.7671)$ \\
Large firm & $0.0520^{* * *}$ & $(0.0331,0.0710)$ \\
Customer density & $0.0049^{* * *}$ & $(0.0036,0.0062)$ \\
Vertical integration & 0.0004 & $(-0.0001,0.0010)$ \\
Small scale production & 0.0003 & $(-0.0004,0.0011)$ \\
Large firm ×small scale production & 0.0002 & $(-0.0015,0.0019)$ \\
Micro scale production & -0.0029 & $(-0.0086,0.0029)$ \\
Power distributed to border point & -0.0006 & $(-0.0017,0.0004)$ \\
Price area SE2 & 0.0144 & $(-0.0326,0.0617)$ \\
Price area SE3 & $-0.0825^{* * *}$ & $(-0.1220,-0.0449)$ \\
Price area SE4 & $-0.1427^{* * *}$ & $(-0.1839,-0.1028)$ \\
y2015 & -0.0183 & $(-0.0390,0.0036)$ \\
y2016 & -0.0022 & $(-0.0238,0.0192)$ \\
y2017 & $0.0282^{* *}$ & $(0.0065,0.0506)$ \\
Sigma & $0.0959^{* * *}$ & $(0.0900,0.1021)$ \\
Log likelihood: 582.1 on 15 degree of freedom. & \\
Number of observations: 606 & &
\end{tabular}

Notes: *,**, and *** represent significance at the 10,5 , and $1 \%$ levels, respectively.

Table C.2

Estimated parameters and confidence intervals for the regression model (dependent variable: $e_{i}$ ). ( $M 1$ with interaction term).

\begin{tabular}{lcl}
\hline Independent variables & Coefficients & Confidence interval (95\%) \\
\hline (Intercept) & $0.7255^{* * *}$ & $(0.6869,0.7662)$ \\
Large firm & $0.0509^{* * *}$ & $(0.0347,0.0674)$ \\
Customer density & $0.0053^{* * *}$ & $(0.0038,0.0068)$ \\
Vertical integration & $0.0005^{*}$ & $(-0.0001,0.0010)$ \\
Small scale production & $0.0017^{* *}$ & $(0.0002,0.0032)$ \\
Customer density $\times$ small scale production & $-0.0002^{*}$ & $(-0.0004,0.0000)$ \\
Micro scale production & -0.0026 & $(-0.0082,0.0032)$ \\
Power distributed to border point & -0.0007 & $(-0.0018,0.0004)$ \\
Price area SE2 & 0.0090 & $(-0.0371,0.0558)$ \\
Price area SE3 & $-0.0823^{* * *}$ & $(-0.1228,-0.0444)$ \\
Price area SE4 & $-0.1441^{* * *}$ & $(-0.1876,-0.1037)$ \\
y2015 & $-0.0186^{*}$ & $(-0.0403,0.0025)$ \\
y2016 & -0.0022 & $(-0.0246,0.0204)$ \\
y2017 & $0.0283^{* *}$ & $(0.0050,0.0511)$ \\
Sigma & $0.0958^{* * *}$ & $(0.0900,0.1019)$ \\
Log likelihood: 582.8 on 15 degree of freedom. & \\
Number of observations: 606 & & \\
\hline
\end{tabular}

Notes: $* * *$, and $* * *$ represent significance at the 10,5 , and $1 \%$ levels, respectively.

Table C.3

Estimated parameters and confidence intervals for the regression model (dependent variable: $e_{i}$ ). $M 1$ without vertical integration.

\begin{tabular}{lcl}
\hline Independent variables & Coefficients & Confidence interval (95\%) \\
\hline Intercept) & $0.7264^{* * *}$ & $(0.6840,0.7680)$ \\
Large firm & $0.0536^{* * *}$ & $(0.0373,0.0705)$ \\
Customer density & $0.0051^{* * *}$ & $(0.0038,0.0064)$ \\
Small scale production & 0.0004 & $(-0.0003,0.0011)$ \\
Micro scale production & -0.0031 & $(-0.0087,0.0030)$ \\
Power distributed to border point & -0.0001 & $(-0.0010,0.0008)$ \\
Price area SE2 & 0.0154 & $(-0.0324,0.0624)$ \\
Price area SE3 & $-0.0811^{* * *}$ & $(-0.1220,-0.0426)$ \\
Price area SE4 & $-0.1411^{* * *}$ & $(-0.1849,-0.0996)$ \\
y2015 & -0.0181 & $(-0.0407,0.0048)$ \\
y2016 & -0.0017 & $(-0.0227,0.0201)$ \\
y2017 & $0.0292^{* *}$ & $(0.0062,0.0518)$ \\
Sigma & $0.0960^{* * *}$ & $(0.0901,0.1020)$ \\
Log likelihood: 581.6 on 13 degree of freedom. & \\
Number of observations: 606 & & \\
\hline
\end{tabular}

Notes: *,**, and *** represent significance at the 10,5 , and $1 \%$ levels, respectively. 
Table C.4

Estimated parameters and confidence intervals for the regression model (dependent variable: $e_{i}$ ). $M 1$ with quadratic small scale production.

\begin{tabular}{lcl}
\hline Independent variables & Coefficients & Confidence interval (95\%) \\
\hline (Intercept) & $0.7305^{* * *}$ & $(0.6898,0.7708)$ \\
Large firm & $0.0525^{* * *}$ & $(0.0361,0.0697)$ \\
Customer density & $0.0047^{* * *}$ & $(0.0035,0.0060)$ \\
Vertical integration & $0.0005^{*}$ & $(-0.0000,0.0011)$ \\
Small scale production & $-0.0014^{*}$ & $(-0.0028,0.0002)$ \\
Small scale production squared & $0.0000^{* *}$ & $(0.0000,0.0001)$ \\
Micro scale production & -0.0018 & $(-0.0077,0.0037)$ \\
Power distributed to border point & -0.0006 & $(-0.0017,0.0005)$ \\
Price area SE2 & 0.0148 & $(-0.0334,0.0609)$ \\
Price area SE3 & $-0.0800^{* * *}$ & $(-0.1206,-0.0411)$ \\
Price area SE4 & $-0.1406^{* * *}$ & $(-0.1839,-0.0993)$ \\
y2015 & -0.0182 & $(-0.0399,0.0051)$ \\
y2016 & -0.0013 & $(-0.0228,0.0217)$ \\
y2017 & $0.0292^{* *}$ & $(0.0066,0.0528)$ \\
Sigma & $0.0956^{* * *}$ & $(0.0897,0.1016)$ \\
Log likelihood: 583.8 on 15 degree of freedom. & \\
Number of observations: 606 & & \\
\hline
\end{tabular}

Notes: *,**, and *** represent significance at the 10,5 , and $1 \%$ levels, respectively.

Table C.5

Estimated parameters and confidence intervals for the regression model (dependent variable: $e_{i}$ ). (M2 with interaction term).

\begin{tabular}{lcl}
\hline Independent variables & Coefficients & Confidence interval (95\%) \\
\hline (Intercept) & $0.5511^{* * *}$ & $(0.5116,0.5918)$ \\
Large firm & $0.0449^{* * *}$ & $(0.0259,0.0635)$ \\
Customer density & $0.0132^{* * *}$ & $(0.0118,0.0147)$ \\
Vertical integration & 0.0001 & $(-0.0004,0.0007)$ \\
Small scale production & -0.0000 & $(-0.0008,0.0007)$ \\
Large firm ×small scale production & 0.0006 & $(-0.0010,0.0022)$ \\
Micro scale production & -0.0007 & $(-0.0065,0.0051)$ \\
Power distributed to border point & $-0.0018^{* * *}$ & $(-0.0028,-0.0007)$ \\
Price area SE2 & $0.0705^{* * *}$ & $(0.0248,0.1175)$ \\
Price area SE3 & $-0.0614^{* * *}$ & $(-0.1002,-0.0219)$ \\
Price area SE4 & $-0.1108^{* * *}$ & $(-0.1515,-0.0690)$ \\
y2015 & -0.0156 & $(-0.0372,0.0059)$ \\
y2016 & -0.0050 & $(-0.0270,0.0173)$ \\
y2017 & $0.0234^{* *}$ & $(0.0017,0.0462)$ \\
Sigma & $0.0958^{* * *}$ & $(0.0903,0.1014)$ \\
Log likelihood: 583.6 on 15 degree of freedom. & \\
Number of observations: 606 & &
\end{tabular}

Notes: * **, and $* * *$ represent significance at the 10,5 , and $1 \%$ levels, respectively.

Table C.6

Estimated parameters and confidence intervals for the regression model (dependent variable: $e_{i}$ ). (M2 with interaction terms).

\begin{tabular}{lcl}
\hline Independent variables & Coefficients & Confidence interval (95\%) \\
\hline (Intercept) & $0.5520^{* * *}$ & $(0.5124,0.5909)$ \\
Large firm & $0.0484^{* * *}$ & $(0.0322,0.0649)$ \\
Customer density & $0.0130^{* * *}$ & $(0.0115,0.0145)$ \\
Vertical integration & 0.0001 & $(-0.0005,0.0007)$ \\
Small scale production & -0.0004 & $(-0.0019,0.0011)$ \\
Customer density $\times$ small scale production & 0.0001 & $(-0.0001,0.0002)$ \\
Micro scale production & -0.0008 & $(-0.0067,0.0047)$ \\
Power distributed to border point & $-0.0017^{* * *}$ & $(-0.0028,-0.0006)$ \\
Price area SE2 & $0.0726^{* * *}$ & $(0.0264,0.1184)$ \\
Price area SE3 & $-0.0616^{* * *}$ & $(-0.1008,-0.0229)$ \\
Price area SE4 & $-0.1104^{* * *}$ & $(-0.1517,-0.0702)$ \\
y2015 & -0.0160 & $(-0.0370,0.0061)$ \\
y2016 & -0.0054 & $(-0.0272,0.0157)$ \\
y2017 & $0.0229^{* *}$ & $(0.0009,0.0456)$ \\
Sigma & $0.0958^{* * *}$ & $(0.0904,0.1013)$ \\
Log likelihood: 583.4 on 15 degree of freedom. & \\
Number of observations: 606 & & \\
\hline
\end{tabular}

Notes: *,**, and *** represent significance at the 10,5 , and $1 \%$ levels, respectively.
Table C.7

Estimated parameters and confidence intervals for the regression model (dependent variable: $e_{i}$ ). $M 2$ without vertical integration.

\begin{tabular}{lcl}
\hline Independent variables & Coefficients & Confidence interval (95\%) \\
\hline Intercept) & $0.5509^{* * *}$ & $(0.5127,0.5911)$ \\
Large firm & $0.0486^{* * *}$ & $(0.0328,0.0651)$ \\
Customer density & $0.0131^{* * *}$ & $(0.0117,0.0146)$ \\
Small scale production & 0.0001 & $(-0.0006,0.0007)$ \\
Micro scale production & -0.0008 & $(-0.0064,0.0050)$ \\
Power distributed to border point & $-0.0016^{* * *}$ & $(-0.0025,-0.0008)$ \\
Price area SE2 & $0.0702^{* * *}$ & $(0.0258,0.1173)$ \\
Price area SE3 & $-0.0610^{* * *}$ & $(-0.1000,-0.0229)$ \\
Price area SE4 & $-0.1102^{* * *}$ & $(-0.1519,-0.0672)$ \\
y2015 & -0.0158 & $(-0.0374,0.0054)$ \\
y2016 & -0.0051 & $(-0.0275,0.0172)$ \\
y2017 & $0.0234^{* *}$ & $(0.0016,0.0461)$ \\
Sigma & $0.0956^{* * *}$ & $(0.0901,0.1015)$ \\
Log likelihood: 584.4 on 13 degree of freedom. & \\
Number of observations: 606 & & \\
\hline
\end{tabular}

Notes: *,**, and $* * *$ represent significance at the 10,5 , and $1 \%$ levels, respectively.

Table C.8

Estimated parameters and confidence intervals for the regression model (dependent variable: $e_{i}$ ). $M 2$ with quadratic small scale production.

\begin{tabular}{lcl}
\hline Independent variables & Coefficients & Confidence interval (95\%) \\
\hline (Intercept) & $0.5537^{* * *}$ & $(0.5176,0.5929)$ \\
Large firm & $0.0483^{* * *}$ & $(0.0311,0.0650)$ \\
Customer density & $0.0129^{* * *}$ & $(0.0114,0.0144)$ \\
Vertical integration & 0.0002 & $(-0.0003,0.0008)$ \\
Small scale production & $-0.0014^{*}$ & $(-0.0029,0.0001)$ \\
Small scale production squared & $0.0000^{* *}$ & $(0.0000,0.0000)$ \\
Micro scale production & 0.0003 & $(-0.0055,0.0061)$ \\
Power distributed to border point & $-0.0018^{* * *}$ & $(-0.0028,-0.0007)$ \\
Price area SE2 & $0.0698^{* * *}$ & $(0.0231,0.1172)$ \\
Price area SE3 & $-0.0594^{* * *}$ & $(-0.0973,-0.0225)$ \\
Price area SE4 & $-0.1089^{* * *}$ & $(-0.1491,-0.0683)$ \\
y2015 & -0.0156 & $(-0.0365,0.0047)$ \\
y2016 & -0.0046 & $(-0.0259,0.0171)$ \\
y2017 & $0.0240^{* *}$ & $(0.0020,0.0467)$ \\
Sigma & $0.0953^{* * *}$ & $(0.0897,0.1009)$ \\
Log likelihood: 586.5 on 15 degree of freedom. & \\
Number of observations: 606 & & \\
\hline
\end{tabular}

Notes: *, $* *$, and $* * *$ represent significance at the 10,5 , and $1 \%$ levels, respectively.

Table C.9

Estimated relation between costs for netloss and small scale production.

\begin{tabular}{lllll}
\hline & Estimate & Std. Error & $\mathrm{t}$ value & $\operatorname{Pr}(>|t|)$ \\
\hline (Intercept) & 15.3948 & 0.2298 & 66.99 & 0.0000 \\
Small scale production & -0.0616 & 0.0151 & -4.07 & 0.0001 \\
\hline
\end{tabular}

\section{References}

Adefarati, T., Bansal, R., 2016. Integration of renewable distributed generators into the distribution system: a review. IET Renew. Power Gener. 10 (7), 873-884.

Agrell, P., Bogetoft, P., Tind, J., 2005. DEA And dynamic yardstick competition in scandinavian electricity distribution. J. Prod. Anal. 23 (2), 173-201.

Arocena, P., 2008. Cost and quality gains from diversification and vertical integration in the electricity industry: a DEA approach. Energy Econ 30 (1), 39-58.

Asrari, A., Wu, T., Lotfifard, S., 2016. The impacts of distributed energy sources on distribution network reconfiguration. IEEE Trans. Energy Convers. 31 (2), 606-613.

Banker, R.D., Natarajan, R., 2008. Evaluating contextual variables affecting productivity using data envelopment analysis. Oper. Res 56 (1), 48-58.

Bobde, S.M., Tanaka, M., 2018. Efficiency evaluation of electricity distribution utilities in India: A two-stage DEA with bootstrap estimation. J. Oper. Res. Soc. 69 (9), 1423-1434.

Çelen, A., 2013. Efficiency and productivity (TFP) of the turkish electricity distribution companies: an application of two-stage (DEA\&Tobit) analysis. Energy Policy 63, 300-310.

Cossent, R., Gómez, T., Frías, P., 2009. Towards a future with large penetration of distributed generation: is the current regulation of electricity distribution ready? Regulatory recommendations under a European perspective. Energy Policy 37 (3), $1145-1155$.

Dai, X., Kuosmanen, T., 2014. Best-practice benchmarking using clustering methods: application to energy regulation. Omega 42 (1), 179-188. 
Daraio, C., Simar, L., Wilson, P.W., 2018. Central limit theorems for conditional efficiency measures and tests of the separability condition in non-parametric, two-stage models of production. Econom. J. 21 (2), 170-191.

Edvardsen, D.F., Førsund, F.R., 2003. International benchmarking of electricity distribution utilities. Resour. Energy Econ. 25 (4), 353-371.

Energimarknadsinspektionen, 2015. Methods for determining efficiency improvement requirements in the revenue regulator of electricity distribution (Swedish title: Metodik för bestämning av effektiviseringskrav i intäktsramsregleringen för elnätsföretag). Energimarknadsinspektionen.

Energimyndigheten, 2018. Scenarios for Sweden's energy system (Swedish title: Scenarier över sveriges energisystem energimyndigheten).

Fallahi, A., et al., 2019. Application of a robust data envelopment analysis model for performance evaluation of electricity distribution companies. Int. J. Energy Sect. Manag.

Filippini, M., Greene, W., Masiero, G., 2018. Persistent and transient productive inefficiency in a regulated industry: electricity distribution. Energy Econ. 69, 325-334.

Førsund, F.R., Kittelsen, S.A., 1998. Productivity development of norwegian electricity distribution utilities. Resour. Energy Econ. 20 (3), 207-224.

Giannakis, D., Jamasb, T., Pollitt, M., 2005. Benchmarking and incentive regulation of quality of service: an application to the UK electricity distribution networks. Energy policy 33 (17), 2256-2271.

Hjalmarsson, L., Veiderpass, A., 1992. Productivity in Swedish electricity retail distribution. Scand. J. Econ. S193-S205.

Jenkins, J.D., Pérez-Arriaga, I.J., et al., 2017. Improved regulatory approaches for the remuneration of electricity distribution utilities with high penetrations of distributed energy resources. Energy J. 38 (3), 63-91.

Korhonen, P.J., Syrjänen, M.J., 2003. Evaluation of cost efficiency in finnish electricity distribution. Ann. Oper. Res. 121 (1-4), 105-122.
Kumbhakar, S.C., Lien, G., 2017. Yardstick regulation of electricity distributiondisentangling short-run and long-run inefficiencies. Energy J. 38 (5).

Kumbhakar, S.C., et al., 2020. Disentangling costs of persistent and transient technical inefficiency and input misallocation: The case of norwegian electricity distribution firms. Energy J. 41 (3).

Kuosmanen, T., 2012. Stochastic semi-nonparametric frontier estimation of electricity distribution networks: application of the stoned method in the finnish regulatory model. Energy Econ. 34 (6), 2189-2199.

Lindahl, J., 2016. National survey report of PV power applications.

Llorca, M., Orea, L., Pollitt, M.G., 2014. Using the latent class approach to cluster firms in benchmarking: An application to the US electricity transmission industry. Oper Res. Perspect. 1 (1), 6-17.

Lundin, E., 2020. Effects of privatization on price and labor efficiency: the swedish electricity distribution sector. Energy J. 41 (2).

Mateo, C., et al., 2018. Impact of solar PV self-consumption policies on distribution networks and regulatory implications. Sol. Energy 176, 62-72.

Mydland, $\emptyset$., et al., 2019. Economies of scope and scale in the norwegian electricity industry. Econ. Model.

Pandur, S., Jonsson, D., 2015. Energimarknadsinspektionens föreskrifter om intäktsramar för elnätsföretag. Ei R 2015.

Simar, L., Wilson, P.W., 2007. Estimation and inference in two-stage, semi-parametric models of production processes. J. Econometrics 136, 31-64.

Simar, L., Wilson, P.W., 2011. Two-stage DEA: caveat emptor. J. Prod. Anal. 36 (2), 205.

Wallnerström, C.J., Grahn, E., Johansson, T., 2017. Analyses of the current Swedish revenue cap regulation. CIRED-Open Access Proc. J. 2017 (1), 2606-2610.

Xie, B.-C., et al., 2018. Measuring the efficiency of grid companies in China: A bootstrapping non-parametric meta-frontier approach. J. Clean. Prod. 174, 1381-1391.

Zhang, S., Lundgren, T., Zhou, W., 2016. Energy efficiency in Swedish industry: A firm-level data envelopment analysis. Energy Econ. 55, 42-51. 